Burnout Survey

\title{
$\Theta$ The Effect of COVID-19 on Interventional Pain Management Practices: A Physician Burnout Survey
}

Sachin "Sunny" Jha, MD, MS1, Shalini Shah, MD², Michael David Calderon, MS, Amol Soin, $\mathrm{MD}^{4}$, and Laxmaiah Manchikanti, MD

From: ${ }^{1}$ University of Southern California, Department of Anesthesiology, Los Angeles, CA; 2,3 University of California, Irvine, Department of Anesthesiology, Orange, $\mathrm{CA} ;{ }^{4}$ Ohio Pain Clinic, Centerville, $\mathrm{OH}$, Wright State University, Dayton, $\mathrm{OH}$; 5 Pain Management Centers of America, Paducah, KY

Address Correspondence: Amol Soin, MD Ohio Pain Clinic 7076 Corporate Way Dayton, $\mathrm{OH} 45458$

E-mail:drsoin@gmail.com

Disclaimer: There was no external funding in the preparation of this manuscript.

Conflict of interest: Dr. Shah is a consultant for Masimo

Corporation and a speaking consultant for Allergan Corporation.

Manuscript received: 05-22-2020 Accepted for publication: 06-15-2020

Free full manuscript: www.painphysicianjournal.com
Background: Burnout has been a commonly discussed issue for the past ten years among physicians and other health care workers. A survey of interventional pain physicians published in 2016 reported high levels of emotional exhaustion, often considered the most taxing aspect of burnout. Job dissatisfaction appeared to be the leading agent in the development of burnout in pain medicine physicians in the United States. The COVID-19 pandemic has drastically affected the entire health care workforce and interventional pain management, with other surgical specialties, has been affected significantly. The COVID-19 pandemic has placed several physical and emotional stressors on interventional pain management physicians and this may lead to increased physician burnout.

Objective: To assess the presence of burnout specific to COVID-19 pandemic among practicing interventional pain physicians.

Methods: American Society of Interventional Pain Physicians (ASIPP) administered a 32 question survey to their members by contacting them via commercially available online marketing company platform. The survey was completed on www.constantcontact.com.

Results: Of 179 surveys sent, 100 responses were obtained. The data from the survey demonstrated that $98 \%$ of physician practices were affected by COVID and $91 \%$ of physicians felt it had a significant financial impact. Sixty seven percent of the physicians responded that inhouse billing was responsible for their increased level of burnout, whereas $73 \%$ responded that electronic medical records (EMRs) were one of the causes. Overall, 78\% were very concerned Almost all respondents have been affected with a reduction in interventional procedures. $60 \%$ had a negative opinion about the future of their practice, whereas $66 \%$ were negative about the entire health care industry.

Limitations: The survey included only a small number of member physicians. Consequently, it may not be generalized for other specialties or even pain medicine. However, it does represent the sentiment and present status of interventional pain management.

Conclusion: The COVID-19 pandemic has put interventional pain practices throughout the United States under considerable financial and psychological stress. It is essential to quantify the extent of economic loss, offer strategies to actively manage provider practice/wellbeing, and minimize risk to personnel to keep patients safe.

Key Words: Interventional pain management, burnout, interventional pain physician, corona COVID-19, financial stress, anxiety, depression

Pain Physician 2020: 23:S271-S282 
D) urnout has traditionally been defined as "a work-related syndrome involving emotional exhaustion, depersonalization, and a sense of reduced personal accomplishment" (1). This has been a growing crisis in the medical community with surveys suggesting the incidence as high as $50 \%$ among practicing physicians (2). Burnout among physicians can manifest as job dissatisfaction, increased risk of medical errors, malpractice lawsuits, and a potential for substance misuse and suicidal ideation (3). Circumstances that are seemingly beyond a physician's control can also contribute to burnout (4). A study published in 2016 examined burnout among interventional pain physicians and noted that $60.4 \%$ reported high emotional exhaustion, 35.7\% reported high depersonalization, and $19.3 \%$ reported low personal accomplishment (5).

In late 2019, COVID-19, a novel coronavirus, began to spread worldwide leading to a global pandemic becoming declared by the World Health Organization on March 11, 2020 (6). COVID-19 spread throughout the United States leading to stay-at-home restrictions being ordered throughout the country limiting individuals to only work in essential roles or leave their residence to perform a limited set of activities. The healthcare system was also impacted by elective procedures and office visits being restricted (7).

These activities have impacted the entire health care community with economic recession, multiple health consequences, and, finally, physician burnout (8-16). The studies have demonstrated issues related to economic recovery after COVID-19 pandemic for orthopedic surgeries $(9,10)$ and some guidelines have focused on emergent or urgent and elective cases with advice for clinical practices (10-13), with one specific guideline providing risk mitigation and stratification strategies for safe return to opening of interventional pain management practices, along with telehealth services (15). In similar fashion, the COVID-19 pandemic has affected many interventional pain physicians and their practices in an unprecedented fashion to stop interventional pain procedures almost entirely and continue with only telehealth visits, causing significant financial, physical, and psychological stress.

Interventional pain management is a subspecialty of medicine defined by the National Uniform Claims Committee (NUCC) as "the discipline of medicine devoted to the diagnosis and treatment of pain related disorders principally with the application of interventional techniques in managing subacute, chronic, persistent, and intractable pain, independently or in conjunction with other modalities of treatment" (16). Similarly, interventional techniques were defined by MedPAC as, "minimally invasive procedures including, percutaneous precision needle placement, with placement of drugs in targeted areas or ablation of targeted nerves; and some surgical techniques such as laser or endoscopic diskectomy, intrathecal infusion pumps and spinal cord stimulators, for the diagnosis and management of chronic, persistent or intractable pain" (17).

Interventional pain management physicians provide extensive services to chronic pain patients in multiple settings with non-invasive interventional modalities, structured exercise program, physical medicine modalities, adjuvant drug therapy, and opioids (1839). Lack of access to interventional techniques may result in increased levels of opioid usage, and drug abuse patterns. The literature is replete with adverse consequence of opioids, including deaths, which have been controlled in recent years (19,38-44). Further, this control may decelerate, once again succumbing to increases in opioid therapy, in addition to increased availability of the opioids on the street with illicit use of prescription drugs.

Severe unprecedented economic health and psychological stress has been noted to cause significant burnout among interventional pain physicians. Thus, with a baseline burnout level already high among interventional pain physicians, the American Society of Interventional Pain Physicians (ASIPP) sought to survey the membership to characterize the degree of burnout exacerbation and specific features related to the COVID-19 pandemic.

\section{Methods}

This study was an observational, prospective, and non-comparative study design. Considering the nature of the survey and lack of disclosure of information, within the limits of the Health Insurance Portability and Accountability Act (HIPAA) and other regulations, Institutional Review Board (IRB) approval was not sought. Interventional pain physicians who were active members in good standing with ASIPP during COVID-19 crisis, were recruited through registered email addresses. Emails introduced the study and provided a link to the survey via www.constantcontact.com.

\section{Measurements}

In total, a 32-question survey (Appendix Table 1) was distributed via commercially available online 
marketing company platform - Constant Contact ( ) - to 179 members of ASIPP. Survey responses were made anonymous, tallied, reported in ratios (\%), and stratified by state based on Census Bureau-designated regions. Some questions (Q7 - Q8, Q16 - Q18, and Q20) allowed multiple answer selections, and partial answers ( $2-5$ individuals) were included in the overall analysis. Free responses (Q25, Q28) were manually reviewed to identify keywords and reported as counts/ratios in the corresponding tables.

\section{RESULTS}

One hundred surveys (55.9\% response rate) were electronically submitted during the month of April $(4 / 16 / 2020$ - 4/28/2020) using the available link on the ASIPP website. A summary of the responder demographics is provided in Table 1 . Overall, $95 \%$ of responders reported a median [25th percentile, 75th percentile] of $2[1,4]$ physicians - including oneself — providing care in their primary practice. Additionally, $93 \%$ of respondents reported a median of $2[1,3]$ mid-level providers,

Table 1. A demographic summary of pain providers that completed the survey.

\begin{tabular}{|c|c|c|c|}
\hline Question & Response & Total & $(\%)$ \\
\hline \multirow[t]{2}{*}{ Gender: } & Male & 81 & $81 \%$ \\
\hline & Female & 19 & $19 \%$ \\
\hline \multirow{5}{*}{ Age: } & $<35$ & 3 & $3 \%$ \\
\hline & $35-44$ & 20 & $20 \%$ \\
\hline & $45-54$ & 27 & $27 \%$ \\
\hline & $55-64$ & 42 & $42 \%$ \\
\hline & $>=65$ & 8 & $8 \%$ \\
\hline \multirow{3}{*}{ Are you an: } & Employer/Owner & 68 & $68 \%$ \\
\hline & Employee & 31 & $31 \%$ \\
\hline & No Response & 1 & $1 \%$ \\
\hline \multirow{4}{*}{ Place of Service: } & Office & 89 & $89 \%$ \\
\hline & Ambulatory Surgery Center & 47 & $47 \%$ \\
\hline & Hospital & 20 & $20 \%$ \\
\hline & Other & 2 & $2 \%$ \\
\hline \multirow{4}{*}{ Primary Practice: } & Interventional Pain Management & 94 & $94 \%$ \\
\hline & Pain Management & 17 & $17 \%$ \\
\hline & Anesthesiology & 8 & $8 \%$ \\
\hline & Physical Medicine and Rehabilitation & 10 & $10 \%$ \\
\hline \multirow{5}{*}{ Percentage of Practice of IPM } & $<=25 \%$ & 5 & $5 \%$ \\
\hline & $26-50$ & 8 & $8 \%$ \\
\hline & $51-75$ & 19 & $19 \%$ \\
\hline & $>=76$ & 68 & $68 \%$ \\
\hline & No Response & 0 & $0 \%$ \\
\hline \multirow{7}{*}{ Number of Years Practicing } & $<5$ & 8 & $8 \%$ \\
\hline & $5-10$ & 13 & $13 \%$ \\
\hline & $10-15$ & 18 & $18 \%$ \\
\hline & $15-20$ & 16 & $16 \%$ \\
\hline & $20-30$ & 36 & $36 \%$ \\
\hline & $>=31$ & 9 & $9 \%$ \\
\hline & No Response & 0 & $0 \%$ \\
\hline
\end{tabular}


e.g., physician assistants (PAs) or advanced registered nurse practitioners (ARNPs) available to assist with the daily workload. A majority of the respondents were male $(81 \%)$ between the ages of $55-64(42 \%)$ that are owners of interventional pain management offices that have been practicing medicine for the last 25 to 30 years.

Among the responders, $35 \%$ of the surveys were from the Northeast region of the United States, while $23 \%, 19 \%$ and $22 \%$ were completed by clinicians in the Midwest, South and West regions respectively. At the time of the survey, the northeast and west were most largely impacted by COVID.

As shown in Table 2, regarding the operational and economic impact, an overwhelming majority of provid- ers $(98 \%)$ report that COVID-19 has impacted their operations. The top 3 modifications in practice were a transition to high-fidelity (video and audio) telemedicine $(77 \%)$, completely stopping all procedures except for emergencies $(60 \%)$, and low-fidelity telemedicine (audio only) consultations (36\%). Of note, none of the respondents report their practice performing normally. Most providers $(91 \%)$ have seen a reduction in collections and are monitoring/reducing spending due to uncertainty (77\%).

In addition, $67 \%$ of the respondents felt that billing and coding in-house was responsible for stress and burnout, whereas only $32 \%$ felt that outsourcing was responsible for their stress. In addition, $73 \%$ responded

Table 2. Provider responses related to impact on business, caseload, and reported burnout.

\begin{tabular}{|c|c|c|c|}
\hline Question & Response & Total & $(\%)$ \\
\hline \multirow{3}{*}{ Have your operations been impacted by COVID-19? } & Yes & 98 & $98 \%$ \\
\hline & No & 0 & $0 \%$ \\
\hline & No response & 2 & $2 \%$ \\
\hline \multirow{8}{*}{ Changes in Operations: } & We have had to close office & 19 & $19 \%$ \\
\hline & Telemedicine (Using video/audio) & 77 & $77 \%$ \\
\hline & Telemedicine (Using audio only) & 36 & $36 \%$ \\
\hline & We have stopped all procedures except emergencies & 60 & $60 \%$ \\
\hline & $\begin{array}{l}\text { We have been performing at reduced }<20 \% \text { volume of } \\
\text { procedures }\end{array}$ & 28 & $28 \%$ \\
\hline & We have been performing less than $50 \%$ of procedures & 19 & $19 \%$ \\
\hline & We have been performing normally & 0 & $0 \%$ \\
\hline & Other & 4 & $4 \%$ \\
\hline \multirow{4}{*}{ Changes in Workforce: } & $\begin{array}{l}\text { We have (or anticipate) reduced staffing through furloughs } \\
\text { and/or layoffs }\end{array}$ & 55 & $56 \%$ \\
\hline & We have reduced hours per staff & 67 & $68 \%$ \\
\hline & We have changed our current/future hiring plans & 41 & $42 \%$ \\
\hline & Staff are allowed to work remotely & 45 & $46 \%$ \\
\hline \multirow{5}{*}{ Changes in Finances: } & We have seen a reduction in collections & 89 & $91 \%$ \\
\hline & We are planning to suspend or significantly curtail operations & 28 & $29 \%$ \\
\hline & We are monitoring/reducing spending due to uncertainty & 75 & $77 \%$ \\
\hline & Other financial changes: & 6 & $6 \%$ \\
\hline & Other & 13 & $13 \%$ \\
\hline \multirow{3}{*}{ Billing and Coding: } & In-house & 67 & $67 \%$ \\
\hline & Outsourced & 32 & $32 \%$ \\
\hline & No Response & 1 & $1 \%$ \\
\hline \multirow{4}{*}{ Documentation: } & EMR & 73 & $73 \%$ \\
\hline & Transcription & 2 & $2 \%$ \\
\hline & Both & 22 & $22 \%$ \\
\hline & No Response & 3 & $3 \%$ \\
\hline
\end{tabular}


that electronic medical records (EMR) was responsible for burnout, whereas $22 \%$ felt that EMR and transcription were responsible for burnout with only $2 \%$ claiming transcription being the cause of burnout.
Table 3, shows the personal, operational, and financial outlook. As expected, $78 \%$ of clinicians express that other providers should be very concerned. Providers anticipate that the most challenging task will be

Table 3. Personal, operational, and financial outlook.

\begin{tabular}{|c|c|c|c|}
\hline \multirow{4}{*}{ How concerned should providers be? } & Very concerned & 78 & $78 \%$ \\
\hline & Moderately concerned & 20 & $20 \%$ \\
\hline & Not concerned & 1 & $1 \%$ \\
\hline & No response & 1 & $1 \%$ \\
\hline \multirow{5}{*}{$\begin{array}{l}\text { Which of the following will be most } \\
\text { challenging? }\end{array}$} & Having enough clinicians or caregivers & 21 & $22 \%$ \\
\hline & Maintaining an adequate stockpile of supplies & 49 & $52 \%$ \\
\hline & Maintaining an adequate stockpile of PPE's for patients and staff & 55 & $58 \%$ \\
\hline & Caring for patients exposed to COVID-19 & 46 & $48 \%$ \\
\hline & Other & 24 & $25 \%$ \\
\hline \multirow{4}{*}{$\begin{array}{l}\text { What is your outlook on the long-term impact } \\
\text { of coronavirus (COVID-19) on your practice? }\end{array}$} & Positive & 16 & $16 \%$ \\
\hline & Negative & 60 & $60 \%$ \\
\hline & Neutral & 23 & $23 \%$ \\
\hline & No Response & 1 & $1 \%$ \\
\hline \multirow{4}{*}{$\begin{array}{l}\text { What is your outlook on the long-term impact } \\
\text { of coronavirus (COVID-19) on healthcare } \\
\text { industry? }\end{array}$} & Positive & 17 & $17 \%$ \\
\hline & Negative & 66 & $66 \%$ \\
\hline & Neutral & 15 & $15 \%$ \\
\hline & No Response & 2 & $2 \%$ \\
\hline \multirow{3}{*}{$\begin{array}{l}\text { Have you felt burned out from practicing } \\
\text { medicine at any point during your career? }\end{array}$} & Yes & 76 & $76 \%$ \\
\hline & No & 23 & $23 \%$ \\
\hline & No Response & 1 & $1 \%$ \\
\hline \multirow{3}{*}{ Do you feel burned out right now? } & Yes & 52 & $52 \%$ \\
\hline & No & 46 & $46 \%$ \\
\hline & No Response & 2 & $2 \%$ \\
\hline \multirow{3}{*}{$\begin{array}{l}\text { Have you avoided expressing feelings of } \\
\text { burnout because you're afraid of being judged } \\
\text { negatively by peers? }\end{array}$} & Yes & 34 & $34 \%$ \\
\hline & No & 63 & $63 \%$ \\
\hline & No Response & 3 & $3 \%$ \\
\hline \multirow{3}{*}{$\begin{array}{l}\text { Have your feelings of burnout ever made you } \\
\text { want to quit practicing medicine? }\end{array}$} & Yes & 55 & $55 \%$ \\
\hline & No & 44 & $44 \%$ \\
\hline & No Response & 1 & $1 \%$ \\
\hline \multirow{5}{*}{ Provider pay/salaries for physicians: } & Guarantee & 11 & $11 \%$ \\
\hline & Guarantee + Bonus & 15 & $15 \%$ \\
\hline & Production & 54 & $54 \%$ \\
\hline & Guarantee + Production & 19 & $19 \%$ \\
\hline & No Response & 1 & $1 \%$ \\
\hline \multirow{5}{*}{ Provider pay/salaries for PAs and ARNPs: } & Guarantee & 37 & $37 \%$ \\
\hline & Guarantee + Bonus & 26 & $26 \%$ \\
\hline & Production & 5 & $5 \%$ \\
\hline & Guarantee + Production & 16 & $16 \%$ \\
\hline & No Response & 16 & $16 \%$ \\
\hline
\end{tabular}


maintaining adequate personal protective equipment (PPE) for patients and staff (58\%), adequate stockpile of supplies (52\%), and caring for COVID-19 exposed patients $(48 \%)$ respectively. Unfortunately, a majority of responders (60\%) believe COVID-19 will have a negative long-term impact on their practice and the overall healthcare industry (66\%).

Questions related to surveying mental, emotional, or physical exhaustion suggest that more than half (52\%) of physicians feel burned out, however a high majority (76\%) report previously feeling this way earlier in their career. When reviewing the written feedback of what has contributed most to being in this state of exhaustion, the top three reasons were attributed to financial stress $(23 \%)$, administrative burden (11\%), and uncertainty (12\%) respectively. Additionally, when asked what the solution to physician burnout is, the top 3 responses were healthcare reform $(35 \%)$, work-life balance $(14 \%)$ and decreased administrative burden (13\%).Summary of salient results are shown in Fig.1.

\section{Discussion}

Approximately 7 weeks after the WHO declared novel coronavirus (COVID-19) a pandemic, ASIPP surveyed the general impact on interventional pain practices during the month of April 2020. At the time this manuscript was written, the pandemic had significantly impacted essentially every interventional pain practice throughout the United States. This disruption has led to a stark transition to telemedicine, significant financial stress, with concerns over PPE supplies. It is worth mentioning that the free responses provide a glimpse into what may broadly impact physician burnout. While a portion of the respondents ( $9 \%$ ) do not consider themselves exhausted, the general inquiry warrants further investigation to disentangle whether something such as financial stress (payer reimbursement, reduced revenue, overhead costs etc.) is elevated specifically due to COVID-19 from baseline. Simultaneously, it is unclear whether the suggested solutions to physician burnout are specific to the facility, overall healthcare industry e.g. Healthcare Reform on a local/systemic level or aimed in response to COVID-19. There are many causes of additional stress to interventional pain management physicians during this time. Economic stresses on the practice of pain management and financial losses in the economy may place a burden on physicians and their practices. The survey revealed that $91 \%$ of physicians will see a reduction in collections. It seems most physicians have awareness and concerns about collections and as a result $77 \%$ of those surveyed mentioned they would be monitoring or reducing spending due to uncertainty. Some of this reduction in spending is coming at the expense of the staff in a physician clinic as $56 \%$ of those surveyed anticipate a reduction in staffing through furloughs and/or layoffs and another $68 \%$ have reduced staff hours. In addition, the survey also shows that billing and coding in house and EMR systems are responsible for significant stressors with $67 \%$ and $73 \%$, respectively.

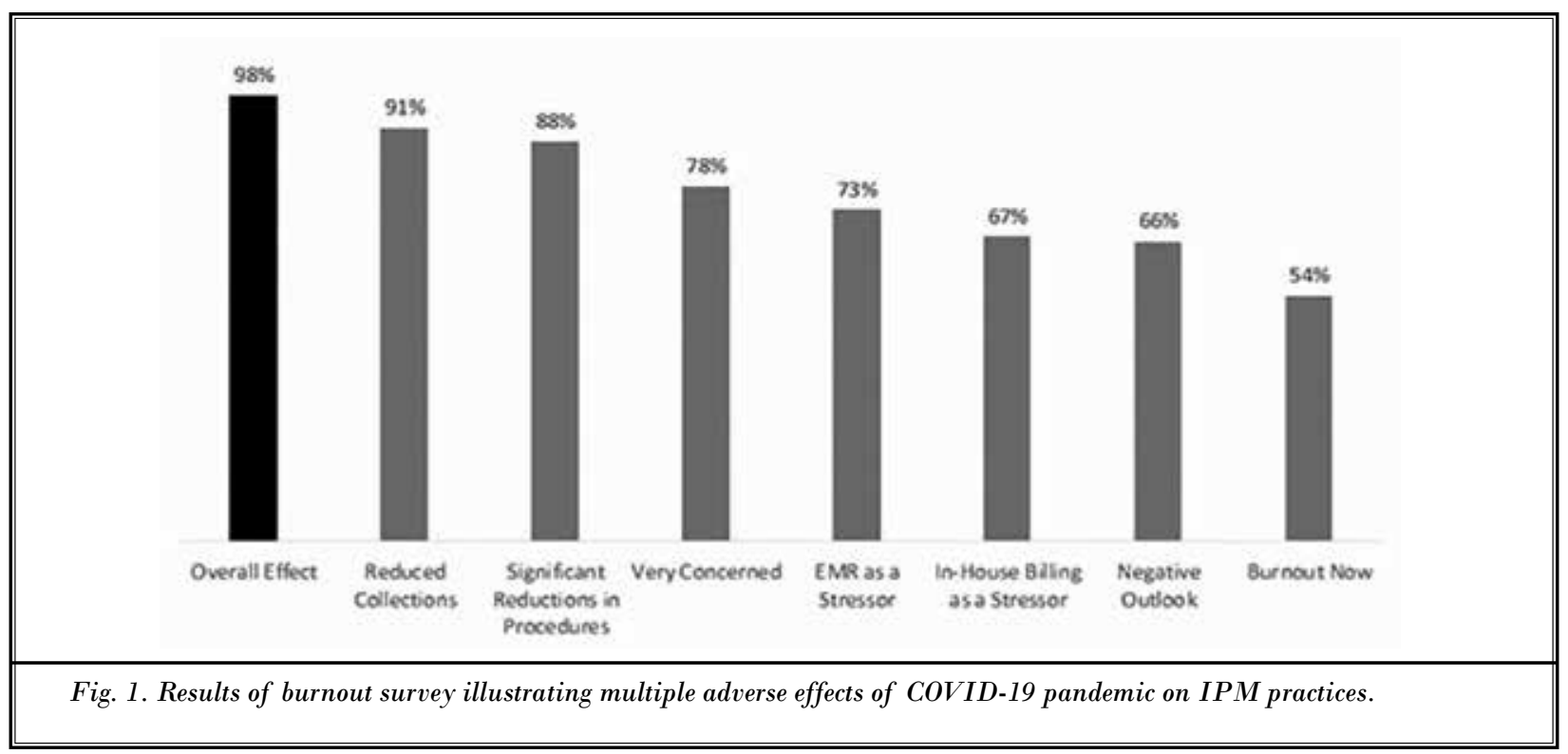


Further, stressors at home with things like daycare or the handling of homeschooling children may be stressors outside of the practice of medicine. The uncertainty of how long COVID-19 will last and its long-term impact also places stress on practicing physicians.

Other surveys have shown similar effect on health care workers. Researchers in China conducted a cross-sectional study published in March 2020, with assessment of 1,257 health care workers in China during the coronavirus pandemic and reported troubling results with $50.4 \%$ having symptoms of depression, $34 \%$ with insomnia, $44.6 \%$ with anxiety, and overall $71.5 \%$ reporting distress $(45,46)$. They also postulated that working in the frontline was an independent risk factor for worse mental health outcomes in all dimensions of interest. Even during regular professional practice, health care professionals have been showing soaring levels of burnout (47). However, burnout in health care professionals is soaring now due to the coronavirus pandemic, which is similar to having the effect of stabbing a fresh wound (45). Due to the pandemic, physicians are required to take on extra workload with an ever-increasing threat of infection, quarantine, and even death. In addition, physicians may be increasing the risk of their family of contracting the virus which is further exacerbated by shortages of PPE. Further, physicians also have to make extremely difficult decisions such as the allocation of critical materials and supplies. Interventional pain physicians have to worry not only about the financial consequences to their staff and family, but also their patients who will suffer without interventional techniques and restricted assessments among new and pre-existing patients. This may cause the opioid epidemic to explode because many patients may suffer with untreated pain.

It has been stated to think of the pandemic as a marathon, not a sprint. It is difficult to be optimistic about the future considering that the constant threat of lockdowns, political meddling without appropriate assistance or uniformity in assessing the future. Consequently, as shown in this survey, many physicians are willing to retire if they could and a large proportion $(55 \%)$ want to quit. In addition, $66 \%$ had a negative outlook of the long-term impact of COVID on the healthcare industry and $60 \%$ also felt negative about their individual practices.

To survive into the future, there is no magic bullet. It is crucial to stay positive, utilize all available avenues with loan programs and grants, work with your staff and patients, and to practice mitigation and risk stratification strategies for safe practices.

Maurya W. Glaude (48), Associate Director of Field Education and Professor of Practice at Tulane University, speaking to ASIPP membership about managing stress and burnout for healthcare professionals in private practice started with a quote, "At the end of the day, we are all human. We are resilient beings, and we each respond to stress differently. We have our own thermometers for the activation of fight-flight-freeze response." She also described that compassion fatigue, which is state experienced by those helping people in distress with extreme state of tension and preoccupation with the suffering of those being helped to the degree that it is traumatizing for the helper (49). Doctors and other health care providers and a multitude of workers involved in helping others are at risk professionals. She described 9 signs of burnout or secondary traumatic stress as follows:

1. Sadness, depression or apathy

2. Feeling easily frustrated

3. Feeling isolated or disconnected from others

4. Feeling tired, exhausted, or overwhelmed

5. Feeling like a failure or that nothing you can do will help

6. Excessive worry or fear about something bad happening

7. Being easily startled, or "on guard" all of the time

8. Having physical signs of stress (e.g., racing heart)

9. Nightmares or recurrent thoughts about the traumatic situation

She also provided 7 tips for reducing stress as follows:

1. Stay connected (social network, family, friends using technology)

2. Limit exposure while staying informed

3. Take breaks or breathers

4. Walk or run off the extra stress

5. Accept support and sharing support with others

6. Care for yourself (as well as you care for others)

7. Get professional help (Telehealth)

Finally, she closed the presentation stating that, "We are all responsible for self-care."

Dr. Haidar Al-Hakim, an ophthalmologist and physician burnout coach based in the UK, recommended the following (45): 
- Remember your mission

We must learn to accept our present for what it is and have faith that everything happens for a reason.

- $\quad$ Build your resilience

Resilience will assist in bouncing back from stressful situations and viewing difficulties as challenges, with a proactive attitude. Resilience can be learned through practice using your preferred method, whether physical, psychological, or spiritual to help to face adversity. Examples of resilience include yoga, support groups, meditation, breathing exercises, and journaling.

- $\quad$ Focus on the present

Whatever is the present situation one is going through shall end. Consequently, focusing on the present will give an individual the chance to be the best self.

- $\quad$ Be realistic but stay positive.

It is easy to drown in negative, self-talk. "Reclaim your internal narrative and change it from a narrative of fear, division, and destruction to a narrative of construction, healing, and faith"

- Even though difficulties are anticipated, stop them from letting those difficulties turn one's life down.

- Practice self-care. Health care workers must take care of themselves, eat healthy food, stay active, and rest sufficiently between shifts.

- Practice appropriate protective measures for yourself and for your family.

- Practice gratitude. Since even in the darkest times, we have things to be grateful about, thus, we must count our blessings (45).

Whether it is health, family, meaningful work, being grateful will help and pull one through difficult times.

\section{LIMITATIONS}

This pilot survey had a small sample size $(n=179)$ with a moderate response rate so the conclusions may not be widely generalized to other specialties and may not accurately represent the overall physician (underserved/rural) community. Additionally, this survey was completed during the month of April, approximately one month after the World Health Organization declared COVID-19 a pandemic (March 11th, 2020), so these data lack a comparison group to detect if the responses are substantially different before said time point. Additionally, the survey was performed before any of the congressional aid packages had been initiated. Finally, this survey is not a validated tool for assessing physician burnout which - as previously mentioned - warrants further investigation using the appropriate methods e.g. Maslach Burnout InventoryHuman Services Survey.

\section{Conclusion}

Burnout is common among medical professionals, specifically among interventional pain physicians $(5,50)$. This survey demonstrates that the pandemic has drastically affected the physical and mental health of interventional pain professionals with substantial negative attitudes among an overwhelming number of practices $(78 \%)$. Most physicians are negative about the future $(60 \%)$ and more than half want to quit practicing medicine $(55 \%)$. Exacerbating factors for burnout include billing and coding, which was the cause of stress in $67 \%$ of physicians with in-house billing. Documentation through EMRs was a significant cause of stress in $73 \%$ of physicians. Improvements in EMR design can help assuage physician burnout. The COVID-19 pandemic continues to have negative effects on wide swaths of our nation including our pain physician community.

\section{Acknowledgments}

The authors wish to thank Vidyasagar Pampati, MSc for identifying the survey items, Melinda Martin, Director of ASIPP, for mailing the survey, Bert Fellows, MA, Director Emeritus of Psychological Services at Pain Management Centers of America, for manuscript review, and Tonie M. Hatton and Diane E. Neihoff, transcriptionists, for their assistance in preparation of this manuscript. We would like to thank the editorial board of Pain Physician for review and criticism in improving the manuscript.

\section{Author Affiliations}

Dr. Jha is Assistant Clinical Professor of Anesthesiology, University of Southern California, Los Angeles, CA, USA

sunnyjha@gmail.com

Dr. Shah is Vice-Chair and Enterprise Director Pain Services, Department of Anesthesiology \& Perioperative Care, University of California Irvine, Orange, CA, USA shahshalini@gmail.com

Michael Calderon is an Associate Clinical Research 
Specialist, Department of Anesthesiology, University of California, Irvine, Department of Anesthesiology,

Orange, CA, USA

mccalder@hs.uci.edu

Dr. Soin is Medical Director, Ohio Pain Clinic, and Clinical Assistant Professor of Surgery at Wright State University, Dayton, $\mathrm{OH}$, USA. drsoin@gmail.com

Dr. Manchikanti is Co-Director, Pain Management Centers of America, Paducah, KY, Clinical Professor, Anesthesiology and Perioperative Medicine, University of Louisville, Louisville, KY, and Professor of Anesthesiology-Research, Department of Anesthesiology, School of Medicine, LSU Health Sciences Center, New Orleans, LA. drIm@thepainmd.com

\section{Author Contributions}

The study was designed by LM, AS, and *VP.

Manuscript preparation and analysis of data SJ, SS and AS.

All authors contributed to preparation to the manuscript, reviewed, and approved the content with final version.

Compliance with Ethical Standards: All authors declare that he/she has no conflict of interest.

*Vidyasagar Pampati, MSc

\section{References}

1. 1. Maslach C, Jackson SE, Leiter MP. Maslach Burnout Inventory Manual, 3rd ed. Consulting Psychologists Press, Palo Alto, 1996.

2. Shanafelt TD, Hasan O, Dyrbye LN, et al. Changes in burnout and satisfaction with work-life balance in physicians and the general US working population between 2011 and 2014. Mayo Clin Proc 2015; 90:1600-1613.

3. Shanafelt TD, Balch CM, Bechamps $G$, et al. Burnout and medical errors among American surgeons. Ann Surg 2010; 251:995-1000.

4. Karasek R. Job demands, job decision latitude, and mental strain: Implications for job redesign. Administrative Science Quarterly 1979; 24:285-307.

5. Kroll H, Macaulay T, Jesse M. A preliminary survey examining predictors of burnout in pain medicine physicians in the United States. Pain Physician 2016; 19:E689-E696.

6. World Health Organization. WHO Director-General's opening remarks at the media briefing on COVID-19 - 11 March 2020.

https://www.who.int/dg/speeches/ detail/who-director-general-s-openingremarks-at-the-media-briefing-oncovid-19---11-march-2020 Accessed 06/01/2020.

7. Kuy S, Gupta R, Correa R, et al. Best practices for a Covid-19 preparedness plan for health systems. NEJM Catalyst, April 30, 2020.

https://catalyst.nejm.org/doi/
pdf/10.1056/CAT.20.0108 Accessed 06/02/2020.

8. O'Connor CM, Anoushiravani AA, DiCaprio MR, Healy WL, lorio R. Economic recovery after the COVID-19 pandemic: Resuming elective orthopedic surgery and total joint arthroplasty. Arthroplasty 2020; 20:30425-3.

9. Bedard NA, Elkins JM, Brown TS. Effect of Covid-19 on hip and knee arthroplasty surgical volume in the United States. Arthroplasty 2018; 33:3281-3287.

10. Kaye K, Paprottka F, Escudero R, et al. Elective, non-urgent procedures and aesthetic surgery in the wake of SARS COVID-19: Considerations regarding safety, feasibility and impact on clinical management. Aesthetic Plast Surg 2020 May 14 [Epub ahead of print].

11. Mouton C, Hirschmann MT, Ollivier M, Seil R, Menetrey J. COVID-19 - ESSKA guidelines and recommendations for resuming elective surgery. J Exp Orthop 2020; 7:28.

12. Shanthanna $\mathrm{H}$, Strand $\mathrm{NH}$, Provenzano $\mathrm{DA}$, et al. Caring for patients with pain during the COVID-19 pandemic: consensus recommendations from an international expert panel. Anaesthesia 2020; 75:935-944.

13. Cohen SP, Baber ZB, Buvanendran A, et al. Pain management best practices from multispecialty organizations during the COVID-19 pandemic and public health crises. Pain Med 2020 Apr 7 [Epub ahead of print].

14. Shah S, Diwan S, Soin A, et al. Evidence- based risk mitigation/stratification during COVID-19 for return to interventional pain practice: ASIPP guidelines. Pain Physician 2020; 23:S161-S182.

15. Wahezi S, Gonzalez D, Yerra S, et al. Telemedicine during COVID and beyond: A practical guide and best practices multidisciplinary approach for the musculoskeletal physical exam. Pain Physician 2020; 23:S205-S238.

16. The National Uniform Claims Committee. Specialty Designation for Interventional Pain Management- 09.

www.cms.hhs.gov/transmittals/ Downloads/r1779b3.pdf

17. Medicare Payment Advisory Commission. Report to the Congress: Paying for interventional pain services in ambulatory settings. Washington, DC: MedPAC. December. 2001. www.medpac.gov

18. Manchikanti L, Abdi S, Atluri S, et al. An update of comprehensive evidencebased guidelines for interventional techniques of chronic spinal pain: Part II: Guidance and recommendations. Pain Physician 2013; 16:S49-S283.

19. Manchikanti L, Kaye AM, Knezevic NN, et al. Responsible, safe, and effective prescription of opioids for chronic non-cancer pain: American Society of Interventional Pain Physicians (ASIPP) guidelines. Pain Physician 2017: 20:2S:S3-S92.

20. Navani A, Manchikanti L, Albers SL, et al. Responsible, safe, and effective use of 
biologics in the management of low back pain: American Society of Interventional Pain Physicians (ASIPP) guidelines. Pain Physician 2019; 22:S1-S74.

21. Manchikanti L, Kaye AD, Soin A, et al. Comprehensive evidence-based guidelines for facet joint interventions in the management of chronic spinal pain: American Society of Interventional Pain Physicians (ASIPP) guidelines. Pain Physician 2020; 23:S1-S127.

22. Manchikanti L, Sanapati MR, Pampati V, Boswell MV, Kaye AD, Hirsch JA. Update on reversal and decline of growth of utilization of interventional techniques in managing chronic pain in the Medicare population from 2000 to 2018. Pain Physician 2019; 22:521-536.

23. Manchikanti L, Sanapati MR, Pampati $V$, et al. Update of utilization patterns of facet joint interventions in managing spinal pain from 2000 to 2018 in the US fee-for-service Medicare population. Pain Physician 2020; 12:E133-E149.

24. Manchikanti L, Pampati V, Soin A, et al. Trends of expenditures and utilization of facet joint interventions in fee-forservice (FFS) Medicare population from 2009-2018. Pain Physician 2020; 23:S129-S147.

25. Manchikanti L, Soin A, Mann DP, et al. Utilization patterns of facet joint interventions in managing spinal pain: A retrospective cohort study in the US fee-for-service Medicare population. Curr Pain Headache Rep 2019; 23:73.

26. Manchikanti L, Sanapati MR, Soin A, et al. An updated analysis of utilization of epidural procedures in managing chronic pain in the Medicare population from 2000 to 2018. Pain Physician 2020; 12:111-126.

27. Manchikanti L, Soin A, Mann DP, Bakshi S, Pampati V, Hirsch JA. Comparative analysis of utilization of epidural procedures in managing chronic pain in the Medicare population: Pre and post Affordable Care Act. Spine (Phila Pa 1976) 2019; 44:220-232.

28. Manchikanti L, Pampati V, Benyamin RM, Hirsch JA. Declining utilization of percutaneous epidural adhesiolysis in Medicare population: Evidence-based or over-regulated? IPM Reports 2018; 2:9-18.

29. Helm II S, Racz GB, Gerdesmeyer L, et al. Percutaneous and endoscopic adhesiolysis in managing low back and lower extremity pain: A systematic review and meta-analysis. Pain Physician 2016; 19:E245-E282.
30. Manchikanti L, Sanapati J, Pampati V, Kaye AD, Hirsch JA. Utilization of vertebral augmentation procedures in the USA: A comparative analysis in Medicare fee-for-service population pre- and post-2009 trials. Curr Pain Headache Rep 2020; 24:22.

31. Farber SH, Han JL, Petraglia III FW, et al. Increasing rates of imaging in failed back surgery syndrome patients: Implications for spinal cord stimulation. Pain Physician 2017; 20:E969-E977.

32. Farber $\mathrm{SH}, \mathrm{Han} \mathrm{J}$, Elsamadicy AA, et al. Long-term cost utility of spinal cord stimulation in patients with failed back surgery syndrome. Pain Physician 2017; 20:E797-E805.

33. Grider JS, Manchikanti L, Carayannopoulos A, et al. Effectiveness of spinal cord stimulation in chronic spinal pain: A systematic review. Pain Physician 2016; 19: $E_{33}-E_{54}$.

34. Lee JH, Shin KS, Park SJ, et al. Comparison of clinical efficacy between transforaminal and interlaminar epidural injections in lumbosacral disc herniation: A systematic review and meta-analysis. Pain Physician 2018; 21:433-448.

35. Lee $\mathrm{JH}$, Kim DH, Kim DH, et al. Comparison of clinical efficacy of epidural injection with or without steroid in lumbosacral disc herniation: A systematic review and meta-analysis. Pain Physician 2018; 21:449-468.

36. Manchikanti L, Knezevic NN, Parr A, Kaye AD, Sanapati M, Hirsch JA. Does epidural bupivacaine with or without steroids provide long-term relief? A systematic review and meta-analysis. Curr Pain Headache Rep 2020; 24:26.

37. Knezevic NN, Manchikanti L, Vanaparthy R, et al. Lack of superiority of epidural injections with lidocaine with steroids compared to without steroids in spinal pain: A systematic review and meta-analysis. Pain Physician 2020; 23:S239-S270

38. Chakravarthy K, Manchikanti L, Kaye AD, Christo PJ. Reframing the role of neuromodulation therapy in the chronic pain treatment paradigm. Pain Physician 2018; 21:507-513.

39. Manchikanti L, Sanapati J, Benyamin RM, Atluri S, Kaye AD, Hirsch JA. Reframing the prevention strategies of the opioid crisis: Focusing on prescription opioids, fentanyl, and heroin epidemic. Pain Physician 2018; 21:309-326.

40. Sanger $N$, Bhatt $M$, Singhal $N$, et al.
Adverse outcomes associated with prescription opioids for acute low back pain: A systematic review and metaanalysis. Pain Physician 2019; 22:119-138.

41. Moride $Y$, Lemieux-Uresandi D, Castillon $\mathrm{G}$, et al. A systematic review of interventions and programs targeting appropriate prescribing of opioids. Pain Physician 2019; 22:229-240.

42. Kertesz SG, Gordon AJ. A crisis of opioids and the limits of prescription control: United States. Addiction 2019; 114:169-180.

43. Gever J. HHS: Don't withdraw opioids suddenly-Department issues guideline on tapering and discontinuation. MedPage Today, October 10, 2019.

44. Hopkins RE, Bui T, Magliano D, Arnold C, Dooley M. Prescriber education interventions to optimize opioid prescribing in acute care: $A$ systematic review. Pain Physician 2019; 22:E551-E562.

45. Saleh M. A double whammy: The COVID-19 pandemic and burnout in medical professions. Harvard Medical School, Lean Forward, April 9, 2020.

https://leanforward.hms.harvard. edu/2020/04/o9/a-double-whammythe-covid-19-pandemic-and-burnoutin-medical-professionals/ Accessed 6/2/2020.

46. Lai J, Ma S, Wang $Y$, et al. Factors associated with mental health outcomes among health care workers exposed to coronavirus disease 2019. JAMA Netw Open 2020; 3:e203976.

47. World Medical Association. WMA leader warns of global physician burnout. WMA press release. October 5, 2018.

https://www.wma.net/news-post/wmaleader-warns-of-global-physicianburnout/Accessed 6/2/2020.

48. Glaude MW. Managing Stress and Burnout for Healthcare Professionals in Private Practice. Presentation, April 3, 2020

49. Compassion Fatigue: An Expert Interview with Charles R. Figley, MS, PhD. Medscape, October 17, 2005

https://www.medscape.com/ viewarticle/513615 Accessed 6/8/2020.

50. Riquelme I, Chacón JI, Gándara AV, et al. Prevalence of burnout among pain medicine physicians and its potential effect upon clinical outcomes in patients with oncologic pain or chronic pain of nononcologic origin. Pain Med 2018; 19:2398-2407. 
Appendix Table 1: COVID-19 Physician Burnout Questionnaire.

1. Gender:
a. Male
b. Female

2. Age:
a. $<35$
b. $35-44$
c. $45-54$
d. $55-64$
e. $>=65$

3. Specialty:

4. City:

5. State:

6. Are you an:

a. Employer/Owner

b. Employee

c. No Response

7. Place of service:

a. Office Ambulatory

b. Surgery Center

c. Hospital

d. Other

8. Primary practice:
a. Interventional Pain Management
b. Pain Management
c. Anesthesiology
d. Physical Medicine and Rehabilitation
e. Comment

9. Percentage of practice of IPM
a. $<=25 \%$
b. $26-50$
c. $51-75$
d. $>=76$
e. No Response

10. Number of years practicing
a. $<5$
b. $5-10$
c. $10-15$
d. $15-20$
e. $20-30$
f. $>=31$
g. No Response

11. Number of hours work per week:
a. $<20$
b. $21-40$
c. $41-50$
d. $51-60$
e. $>=61$
f. No Response

12. Number of physicians including you:

13. Number of PAs/ARNPs

14. Total Staff:
a. $<10$
b. $10-20$
c. $20-50$
d. $50-100$
e. $100+$

15. Have your operations been impacted by COVID-19?
a. Yes
b. No
c. No response

16. "Changes in operations:"

a. We have had to close office Telemedicine (Using video/ audio)

b. Telemedicine (Using audio only)

c. We have stopped all procedures except emergencies

d. We have been performing at reduced $<20 \%$ volume of procedures

e. We have been performing less than $50 \%$ of procedures

f. We have been performing normally

g. Other

17. "Changes in workforce:"

a We have (or anticipate) reduced staffing through furloughs and/or layoffs

b. We have reduced hours per staff

c. We have changed our current/future hiring plans

d. Staff are allowed to work remotely

18. "Changes in finances:"

a. We have seen a reduction in collection

b. We are planning to suspend or significantly curtail operations

c. We are monitoring/reducing spending due to uncertainty

d. Other financial changes:

e. Other

19. How concerned should providers be?

a. Very concerned

b. Moderately concerned

c. Not concerned

d. No response

20. "Which of the following will be most challenging?"

a. Having enough clinicians or caregivers

b. Maintaining an adequate stockpile of supplies

c. Maintaining an adequate stockpile of PPE's for patients and staff

d. Caring for patients exposed toCOVID-19

e. Other

21. "What is your outlook on the long-term impact of coronavirus (COVID-19) on your practice?"
a. Positive
b. Negative
c. Neutral
d. No Response

22. "What is your outlook on the long-term impact of coronavirus (COVID-19) on healthcare industry?"

a. Positive

b. Negative

c. Neutral

d. No Response

23. "Have you felt burned out from practicing medicine at any point during your career?"
a. Yes
b. No
c. No Response

24. "Do you feel burned out right now?"
a. Yes
b. No
c. No Response

25. "What has contributed the most to your feelings of burnout?" 
26. "Have you avoided expressing feelings of burnout because you're afraid of being judged negatively by peers?"
a. Yes
b. No
c. No Response

27. "Have your feelings of burnout ever made you want to quit practicing medicine?"

a. Yes

b. No

c. No Response

28. "What do you believe is the solution to physician burnout?"

29. Billing and Coding:
a. In-house
b. Outsourced
c. No Response

30. Documentation:
a. EMR Transcription
b. Both
c. No Response

31. "Provider pay/salaries for physicians:"
a. Guarantee
b. Guarantee + Bonus Production
c. Guarantee + Production
d. No Response

32. "Provider pay/salaries for PAs and ARNPs:"
a. Guarantee
b. Guarantee + Bonus
c. Production
d. Guarantee + Production
e. No Response 